\title{
The association between chronological age, age at injury and employment: Is there a mediating effect of secondary health conditions?
}

This article has been corrected since advance online publication and a corrigendum is also printed in this issue.

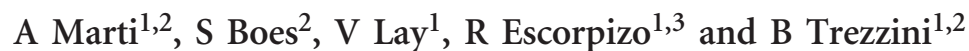

Study design: Cross-sectional observational study with data from the 2012 community-based survey of the Swiss Spinal Cord Injury Cohort Study.

Objectives: To examine the relationships between chronological age, age at injury, secondary health conditions (SHCs) and paid employment.

Setting: Community setting in Switzerland.

Methods: A total of 1159 individuals of working age (16-63 years for women and 64 years for men) with traumatic or non-traumatic spinal cord injury (SCl) were included in the study. Direct and indirect (via SHCs) effects of chronological age and age at injury on paid employment were tested using a decomposition method for logistic regression models.

Results: Both chronological age groups (age 35-49 and 50-63/64 years) and the group with age at injury beyond 40 years showed negative direct effects on employment status. A partial indirect effect (mediation) via chronic pain was found in the group with the highest chronological age (>50 years). Furthermore, pressure ulcer, pain and urinary tract infection were negatively related with employment in both models, that is, chronological age and employment and age at injury and employment.

Conclusion: Being older and having a higher age at injury directly affects whether an individual is employed. Pain is mediating the relation between chronological age and employment. Furthermore, pressure ulcer, chronic pain and urinary tract infection directly reduce the likelihood to be employed and, therefore, represent important intervention targets in efforts to maintain or engage in employment of individuals with $\mathrm{SCl}$.

Spinal Cord (2016) 54, 239-244; doi:10.1038/sc.2015.159; published online 6 October 2015

\section{INTRODUCTION}

The rate of labor market participation (LMP) of individuals with spinal cord injury (SCI) varies widely (3-80\%), depending on the definition of work, country and characteristics of the study sample. ${ }^{1-3}$ Sociodemographics, injury-related variables and environmental factors have been found to influence LMP. ${ }^{1-3}$ Age-related variables such as chronological age, age at injury and time since injury have been found to impact LMP as well. ${ }^{1-4}$ For example, old chronological age is linked to a decrease in organ and immune system function, as well as a decrease in muscular strength, ${ }^{5,6}$ thus contributing to poor outcomes in health, mobility and participation, such as LMP. ${ }^{1,6}$ Older individuals were also found to have a higher risk for secondary health conditions (SHCs) such as pressure ulcers, urinary tract infections, respiratory complications and shoulder pain. ${ }^{7,8}$ With respect to age at injury, career path is often established in younger adults and, if interrupted by a disabling condition, is likely to negatively influence LMP. ${ }^{9}$ In addition, age at injury is important to consider as younger individuals are generally healthier and have a better physiological capacity and hence a higher likelihood to successfully adapt to the disability. ${ }^{6,9}$ With an increase of time since injury, the dysfunction of the nervous system in persons with SCI may lead to further organ impairment and thus may increase the predisposition to SHCs such as pressure ulcer and urinary tract infections. ${ }^{5,7,8}$ Moreover, studies also report an increase in LMP with increasing time since injury. ${ }^{1,3}$

The three variables of chronological age, age at injury and time since injury are thus key indicators to be considered when studying aging with a disability. However, in a cross-sectional setting, because of perfect multicollinearity, only two of these age variables can be included in the same model. ${ }^{4,9}$ This might explain why researchers assessing the importance of these variables in relation to LMP find differing results depending on what age-related variables are controlled for in the model. Previous results suggest, however, that chronological age and age at injury are more important predictors in relation to LMP compared with time since injury; ${ }^{4,10}$ hence, we only included chronological age and age at injury as main predictors in the analysis of our data.

Both chronological age and age at injury are linked to SHCs, which are barriers to employment and job retention. ${ }^{11,12}$ However, there is a lack of knowledge regarding the associations between chronological age, age at injury, SHCs and LMP. Clarifying the underlying relationships among these variables can inform the development of more

${ }^{1}$ Swiss Paraplegic Research (SPF), Nottwil, Switzerland; ${ }^{2}$ Department of Health Sciences and Health Policy, University of Lucerne, Lucerne, Switzerland and ${ }^{3}$ Department of Rehabilitation and Movement Science, The University of Vermont, Burlington, VT, USA

Correspondence: A Marti, Swiss Paraplegic Research (SPF), Guido A Zäch Strasse 4, 6207 Nottwil, Switzerland.

E-mail: albert.marti@paraplegie.ch

Received 26 March 2015; revised 6 August 2015; accepted 10 August 2015; published online 6 October 2015 


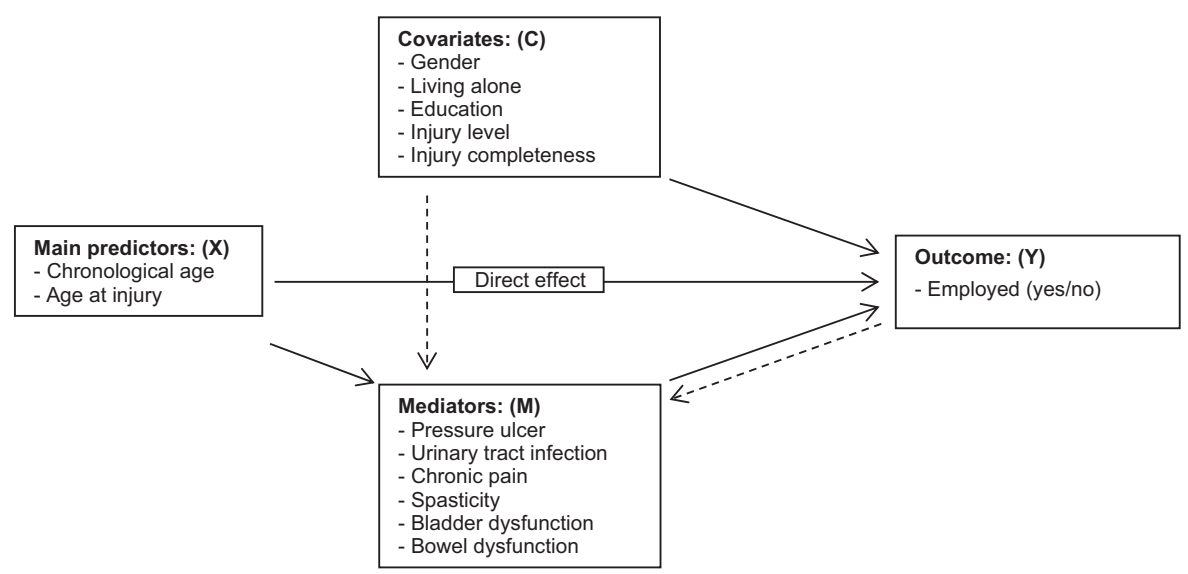

Figure 1 Decomposition and mediation model.

targeted interventions to enhance $\mathrm{LMP}^{7}$ and the prevention and treatment of SHCs to facilitate LMP. Therefore, the objective of this study was to examine the relationships between our main predictors (chronological age and age at injury), SHCs and LMP. The specific aim was to determine the direct and indirect effects of chronological age and age at injury on LMP. We tested the following hypotheses $(\mathrm{H})$ : Study participants with higher chronological age (H1) and older age at injury (H2) have a lower likelihood of being employed. SHCs mediate the effect of chronological age on employment (H3) and the effect of age at injury on employment (H4).

\section{MATERIALS AND METHODS}

\section{Design and participants}

We used cross-sectional observational data from the community-based survey of the Swiss Spinal Cord Injury Cohort Study (SwiSCI) collected in 2012. ${ }^{13}$ The SwiSCI survey is a self-report questionnaire, and consists of a common starter and a basic questionnaire, and three subsequent topic-related modules. SwiSCI included individuals aged 16 years or older who permanently resided in Switzerland and who were diagnosed with traumatic or non-traumatic SCI. ${ }^{13}$ Exclusion criteria for SwiSCI were: congenital conditions leading to SCI; acquiring an SCI in the context of palliative care; neurodegenerative disorders; and individuals with Guillain-Barré syndrome. The study design of SwiSCI is reported elsewhere. ${ }^{13}$ The responsible ethical committee approved the SwiSCI study. For this study, we included individuals of working age as defined by the government (16-63 years for women and age 16-64 years for men). Furthermore, individuals who reported to be solely in education were excluded.

\footnotetext{
Measures

We defined LMP as any paid employment of persons of working age, including those who have paid employment and also receive a partial disability pension benefit. Not considered as employed were volunteers (unpaid work).

SHCs were assessed using an adapted version of the secondary condition scale, ${ }^{14}$ which asked about the occurrence of 14 different SHCs in the past 3 months. Based on interviews with five medical and vocational experts at the Swiss Paraplegic Centre, the following six SCI-related SHCs were most frequently identified as being relevant in the context of LMP: pressure ulcer, urinary tract infection, chronic pain, spasticity and bladder and bowel dysfunction. These findings are consistent with other studies examining SHCs related to LMP. ${ }^{11,12}$ Assuming that only severe SHCs influence LMP, we dichotomized the response categories of 'not experienced or insignificant problem'; 'mild or infrequent problem'; 'moderate or occasional problem'; 'significant or chronic problem' into 'significant or chronic problem (yes/no)'.

Finally, we included self-reported sociodemographic characteristics (i.e. gender, living alone (yes/no)), injury-related information (i.e. SCI level (paraplegia/tetraplegia) and completeness (complete/incomplete SCI)) and years of education as covariates in our analyses.
}

\section{Statistical analyses}

Descriptive statistics were calculated based on complete case data, using Stata version $13 .{ }^{15}$ Incomplete cases (item non-response) were imputed using the $\mathrm{R}$ software package missForest. ${ }^{16}$ We imputed main predictors, SHCs and covariates (sociodemographic and injury-related information, education). Individual non-response was accounted for by using inverse probability weights. Inverse probability weights resulted from propensity scores in multivariable-adjusted logistic regression analyses.

Figure 1 illustrates our hypothesized relationships between the main predictors, covariates, SHCs and LMP. To answer our study hypotheses, we used the KHB (Karlson, Holm, Breen) method ${ }^{17}$ as implemented in Stata's khb ado-file ${ }^{18}$ in combination with logistic regression models. The KHB method is a decomposition method that allows to disentangle the effects of the main predictors into direct and indirect effects (via the SHC variables) and that is unaffected by the rescaling bias that arises in comparisons of nonlinear models. ${ }^{18}$ In a nonlinear probability model, the inclusion of a mediator $\mathrm{M}$ (SHCs) alters the coefficient of $\mathrm{X}$ (main predictor), regardless of whether $\mathrm{M}$ is correlated with X (Figure 1). It is sufficient that M is correlated with Y (LMP). In this case, KHB extracts with a linear regression of $\mathrm{M}$ on $\mathrm{X}$ the information of $\mathrm{M}$ that is not contained in $\mathrm{X}$. The residual information is used instead of $\mathrm{M}$ to calculate the reduced model, which then can be compared with the full model with $\mathrm{X}$ and $\mathrm{M}$ without rescaling bias. ${ }^{18}$ Our mediation approach included the following analysis steps: (1) the total effects (main predictors on LMP, including covariates, but without the SHC mediators) were decomposed into (2) direct effects (main predictors on LMP, including covariates and SHC mediators) and (3) indirect effects (total mediation through SHCs). Finally, we calculated the contribution of each SHC to the total effect. ${ }^{18}$

The relationships between the main predictors and LMP are likely to be nonlinear. ${ }^{5}$ To assess functional forms, and to group the data, we used the nonparametric graphs of the Stata command lpoly in relation to LMP. Accordingly, we grouped chronological age (model 1) into: $\leqslant 34$; 35-49; 50-63/64 years and age at SCI (model 2) into: $\leqslant 16 ; 17-39 ; 40-63 / 64$ years. Finally, to assess the impact of changes in group allocation to the model outcome, we performed sensitivity analyses of \pm 2 years in both main predictors.

\section{RESULTS}

The eligible population in the SwiSCI survey consisted of 3144 individuals, of which a total of $1922(61.1 \%)$ completed the first (starter), and $1549(49.3 \%)$ the second (basic) questionnaire. Of these 1549 participants, 1159 (74.8\%) met the eligibility criteria for our study and were included in the analyses.

\section{Descriptive results}

Tables 1 and 2 show the sample characteristics. Participants had a mean chronological age of 47.2 years $($ s.d. $=10.6)$ and a mean age at injury of 30.0 (s.d.=12.6). Overall, $664(57.3 \%)$ of the participants 
Table 1 Sample sociodemographics and spinal cord injury-related characteristics

\begin{tabular}{|c|c|c|c|}
\hline Variable & Value & $\begin{array}{c}\text { Percent, } \\
\text { mean (s.d.) }\end{array}$ & $\mathrm{N}$ \\
\hline \multirow[t]{4}{*}{ Gender } & Male & 72.6 & 841 \\
\hline & Female & 27.4 & 318 \\
\hline & Missing & 0.0 & 0 \\
\hline & Total & 100.0 & 1159 \\
\hline \multirow[t]{7}{*}{ Marital status } & Single & 33.8 & 392 \\
\hline & Married & 48.3 & 560 \\
\hline & Widowed & 14.7 & 170 \\
\hline & Divorced & 1.6 & 19 \\
\hline & Registered partnership & 0.6 & 7 \\
\hline & Missing & 1.0 & 11 \\
\hline & Total & 100.0 & 1159 \\
\hline \multirow[t]{4}{*}{ Living alone } & Yes & 29.5 & 342 \\
\hline & No & 68.2 & 790 \\
\hline & Missing & 2.3 & 27 \\
\hline & Total & 100.0 & 1159 \\
\hline \multirow[t]{6}{*}{ Education } & Compulsory schooling & 7.3 & 84 \\
\hline & Vocational training & 23.1 & 268 \\
\hline & Secondary education & 48.0 & 556 \\
\hline & University education & 19.9 & 231 \\
\hline & Missing & 1.7 & 20 \\
\hline & Total & 100.0 & 1159 \\
\hline Education & Years & $13.9(3.3)$ & 1139 \\
\hline Age today & & $47.2(10.6)$ & 1159 \\
\hline Age at injury & & $30.0(12.6)$ & 1139 \\
\hline Time since injury (years) & & $17.1(11.8)$ & 1139 \\
\hline \multirow[t]{4}{*}{ Level of spinal cord injury } & Tetraplegia & 30.6 & 355 \\
\hline & Paraplegia & 68.5 & 794 \\
\hline & Missing & 0.9 & 10 \\
\hline & Total & 100.0 & 1159 \\
\hline \multirow[t]{4}{*}{ Completeness } & Complete & 45.2 & 524 \\
\hline & Incomplete & 54.1 & 627 \\
\hline & Missing & 0.7 & 8 \\
\hline & Total & 100.0 & 1159 \\
\hline \multirow{6}{*}{$\begin{array}{l}\text { Secondary health condition is } \\
\text { a significant/chronic problem }\end{array}$} & Chronic pain & 34.1 & 395 \\
\hline & Bladder dysfunction & 23.0 & 267 \\
\hline & Spasticity & 22.3 & 258 \\
\hline & Bowel dysfunction & 18.5 & 215 \\
\hline & Urinary tract infection & 16.2 & 188 \\
\hline & Pressure ulcer & 7.0 & 81 \\
\hline
\end{tabular}

reported being in paid employment and 125 (19.9\%) of those were employed full time. Pain was most frequently indicated as being a significant or chronic problem (34.1\%), followed by bladder dysfunction (23.0\%) and spasticity $(22.3 \%)$.

\section{Decomposition results}

Results of the decomposition analyses are shown in Table 3.

With regard to hypothesis H1 (study participants with higher chronological age have a lower likelihood of being employed),
Table 2 Work-related variable characteristics

\begin{tabular}{|c|c|c|c|c|}
\hline Variable & Value & Percent & $\begin{array}{c}\text { Work (\%) } \\
\text { (s.d.) }\end{array}$ & $\mathrm{N}$ \\
\hline \multirow[t]{11}{*}{ In paid employment } & Yes & 57.3 & $57.9(26.4)$ & $664 / 628^{a, *}$ \\
\hline & No & 41.7 & & 483 \\
\hline & Missing & 1.0 & & 12 \\
\hline & Total & 100.0 & & 1159 \\
\hline & Total paraplegia & 61.6 & $59.2(25.8)$ & $487^{b} / 462^{a}$ \\
\hline & Incomplete paraplegia & 60.4 & $64.9(27.6)$ & $243 / 232$ \\
\hline & Complete paraplegia & 62.7 & $53.4(22.4)$ & $244 / 230$ \\
\hline & Total tetraplegia & 50.0 & $54.5(27.8)$ & $176^{b} / 166^{a}$ \\
\hline & Incomplete tetraplegia & 50.9 & $59.9(30.4)$ & $111 / 105$ \\
\hline & Complete tetraplegia & 48.5 & $45.2(19.6)$ & $65 / 61$ \\
\hline & Working full time & 19.9 & & 125 \\
\hline
\end{tabular}

model 1 showed a $70.9 \%$ decreased likelihood (odds ratio $(\mathrm{OR})=0.291$, $P<0.001)$ to be employed for the oldest age group (50-63/64 years old) and a $49.5 \%$ decreased likelihood $(\mathrm{OR}=0.505, P=0.001)$ for the middle age group (35-49 years old) compared with the reference group including participants 17 to 34 years of age. Supporting our hypothesis $\mathrm{H} 2$, we found a significant direct effect of age at injury on employment status (model 2), with the odds of being employed decreasing by $46.2 \%(\mathrm{OR}=0.538, P<0.033)$ in the group with SCI onset after 40 years old. The effect of chronological age (model 1) on LMP was in the oldest age group (50-63/64 years old) significantly mediated $(\mathrm{H} 3)$ by SHC $(\mathrm{OR}=0.822, P=0.011 ; 13.68 \%$ of total effect $)$, of which pain accounted for the biggest share (11.49\% of total effect). Our H4 states that SHC mediate the effect of age at injury on employment. In model 2, the direct effect of age at injury on employment was not mediated by SHC in either age at injury group.

In the regression analysis, together with chronological age, pressure ulcer $(\mathrm{OR}=0.569, P=0.043)$ urinary tract infection $(\mathrm{OR}=0.545$, $P=0.002)$ and pain $(\mathrm{OR}=0.421, P<0.001)$ were significantly related to employment. Taken together with age at injury, the associations were statistically significant as well $(\mathrm{OR}=0.565, \quad P=0.040$ for pressure ulcer, $\mathrm{OR}=0.532, P=0.002$ for urinary tract infection and $\mathrm{OR}=0.436, P<0.001$ for pain). Furthermore, in combination with chronological age, being male $(\mathrm{OR}=1.795, P<0.001)$, not living alone $(\mathrm{OR}=0.727, P=0.031)$ having a higher education $(\mathrm{OR}=1.193$, $P<0.001)$ and being paraplegic $(\mathrm{OR}=1.813, P<0.001)$ were related with employment. Also together with age at injury, the same four variables, being male $(\mathrm{OR}=1.837, P<0.001)$, not living alone $(\mathrm{OR}=0.720, \quad P=0.026)$, having a higher education $(\mathrm{OR}=1.192$, $P<0.001)$ and being paraplegic $(\mathrm{OR}=1.812, P<0.001)$ were significantly associated with employment.

Sensitivity analyses revealed no change in the direction of effects and no changes in effect sizes that were of concern. However, in the analysis with group allocation minus and also with plus 2 years, the direct effect of the middle age at injury group (15-37/41 years old) became statistically significant (from $P=0.138$ to 0.021 and from $P=0.138$ to 0.012 ) compared with the reported group (17-39 years old).

\section{DISCUSSION}

The purpose of this study was to examine the associations between the main predictors (chronological age and age at injury), SHCs and LMP. 
Our findings showed that participants who are older in terms of their chronological age and older in terms of their age at injury had a lower likelihood to be employed. Moreover, pain mediated the effect of chronological age on LMP in individuals aged 50-63/64 years.

Our results are consistent with other studies $3,11,12$ that show that younger individuals are more likely to be in paid employment compared with those who are older. The premature termination of employment had been found to be due to a combination of factors including the general aging process and SCI-related health effects such as chronic pain and pressure ulcer. ${ }^{2,5,7}$ With increasing age, individuals with a severe disability might experience a disproportionate functional decline (e.g. chronic pain, fatigue, weakness) sooner in life and, therefore, may terminate employment prematurely. ${ }^{5}$ Moreover, as a matter of prioritization, older individuals might be willing to sacrifice employment and leisure activities in their effort to preserve energy for activities of daily living. ${ }^{5}$ In Switzerland, an additional reason for the decline in LMP with increasing age might be the availability of partial disability benefits from the pension system. Compared with systems where only full disability pensions or no disability pensions are available, partial pensions are likely to enhance part-time employment among young individuals with more severe disability. ${ }^{19}$ On the other hand, these individuals with more severe disability experience a functional decline sooner in life and, as mentioned previously, may terminate employment prematurely. ${ }^{5}$ Pain is a significant general problem in individuals aging with a disability. ${ }^{5,8}$ Our findings revealed that chronic pain as an SHC partially mediated the relationship between chronological age and employment status. More specifically, individuals of 50 years and older seem not only at a higher risk to experience pain but this pain seems to also lead to a decrease in the likelihood for employment.

Individuals with SCI onset at a younger age reported a higher likelihood to be employed, which is consistent with findings from other studies. ${ }^{4,10,12}$ As suggested by Krause and Adkins, ${ }^{9}$ a possible explanation could be that the original career path of older individuals had to be altered after SCI and that older individuals have a decreased ability to adapt to challenges of new employment. Another explanation might be that the disability insurance system is more willing to pay for necessary re-education and work place adaptation for individuals with younger age at injury onset, compared with individuals who are close to retirement age, as the former have a longer work career ahead, and investments in young individuals are more likely cost-effective because of the reduced disability pensions in the long term. Finally, the Swiss Accident Insurance mandatorily insures gainfully employed persons, which is not the case for individuals with pediatric onset SCI. Individuals with pediatric onset SCI receive less compensation payments and hence are more likely to be in paid employment to ensure a higher income. ${ }^{10}$ We found no mediating effect of SHCs between age at injury and LMP. This finding somewhat contradicts Krause's ${ }^{20}$ conclusion that older age at injury is related to poorer health and well being. However, as we assessed six specific SHCs and not health in general, our finding warrants further research. Within a cross-sectional setting, and given the availability of partial disability

Table 3 Decomposition results

Mediation model 1: Chronological age and employment (McFaddens pseudo- $R^{2}=0.15 / N=1159$ )

\begin{tabular}{|c|c|c|c|c|c|}
\hline Employed & $O R$ & s.e. & $z$ & $P>z$ & 95\% Conf. interval \\
\hline \multicolumn{6}{|l|}{ Chronological age (years) ${ }^{a}$} \\
\hline $35-49$ & 0.505 & 0.108 & -3.19 & 0.001 & $0.332-0.768$ \\
\hline $50-63 / 64$ & 0.291 & 0.063 & -5.74 & 0.000 & $0.191-0.443$ \\
\hline Pressure ulcer & 0.569 & 0.159 & -2.02 & 0.043 & $0.329-0.983$ \\
\hline Urinary tract infection & 0.545 & 0.109 & -3.04 & 0.002 & $0.369-0.806$ \\
\hline Pain & 0.421 & 0.063 & -5.75 & 0.000 & $0.313-0.565$ \\
\hline Spasticity & 0.867 & 0.145 & -0.86 & 0.391 & $0.625-1.202$ \\
\hline Bladder & 1.008 & 0.180 & 0.05 & 0.963 & $0.711-1.431$ \\
\hline Bowel & 0.867 & 0.159 & -0.78 & 0.438 & $0.605-1.243$ \\
\hline Gender & 1.795 & 0.272 & 3.85 & 0.000 & $1.333-2.417$ \\
\hline Living alone & 0.727 & 0.107 & -2.16 & 0.031 & $0.544-0.971$ \\
\hline Education & 1.193 & 0.029 & 7.15 & 0.000 & $1.136-1.252$ \\
\hline Paraplegic & 1.813 & 0.265 & 4.06 & 0.000 & $1.361-2.416$ \\
\hline Completeness & 1.001 & 0.140 & 0.01 & 0.995 & $0.761-1.316$ \\
\hline \multicolumn{6}{|l|}{ Mediation $^{\mathrm{b}}$} \\
\hline \multicolumn{6}{|l|}{ Chronological age (years) } \\
\hline $35-49$ & 0.889 & 0.066 & -1.59 & 0.111 & $0.769-1.028$ \\
\hline $50-63 / 64$ & 0.822 & 0.064 & -2.53 & 0.011 & $0.707-0.957$ \\
\hline Contribution of each SHC to the total effect $(\%)^{c}$ & & & $35-49$ years & $50-63 / 64$ years & \\
\hline Pressure ulcer & & & -0.16 & 1.24 & \\
\hline Urinary tract infection & & & 2.50 & 0.38 & \\
\hline Pain & & & 11.34 & 11.49 & \\
\hline Spasticity & & & 0.15 & 0.20 & \\
\hline Bladder & & & -0.03 & -0.02 & \\
\hline Bowel & & & 0.90 & 0.39 & \\
\hline Total mediation percentage ${ }^{d}$ & & & 14.70 & 13.68 & \\
\hline
\end{tabular}


Table 3 (Continued)

Mediation model 2: Age at injury and employment (McFaddens pseudo- $R^{2}=0.15 / N=1159$ )

\begin{tabular}{|c|c|c|c|c|c|}
\hline Employed & $O R$ & s.e. & z & $P>z$ & 95\% Conf. interval \\
\hline \multicolumn{6}{|l|}{ Age at injury (years) ${ }^{a}$} \\
\hline $17-39$ & 0.695 & 0.171 & -1.48 & 0.138 & $0.429-1.125$ \\
\hline $40-63 / 64$ & 0.538 & 0.157 & -2.13 & 0.033 & $0.304-0.952$ \\
\hline Pressure ulcer & 0.565 & 0.157 & -2.05 & 0.040 & $0.327-0.974$ \\
\hline Urinary tract infection & 0.532 & 0.106 & -3.16 & 0.002 & $0.359-0.787$ \\
\hline Pain & 0.436 & 0.066 & -5.46 & 0.000 & $0.324-0.587$ \\
\hline Spasticity & 0.846 & 0.142 & -1.00 & 0.319 & $0.610-1.175$ \\
\hline Bladder & 1.010 & 0.180 & 0.06 & 0.956 & $0.713-1.431$ \\
\hline Bowel & 0.861 & 0.158 & -0.82 & 0.415 & $0.600-1.234$ \\
\hline \multicolumn{6}{|l|}{ Chronological age (years) } \\
\hline $35-49$ & 0.549 & 0.118 & -2.78 & 0.005 & $0.359-0.837$ \\
\hline $50-63 / 64$ & 0.348 & 0.080 & -4.60 & 0.000 & $0.223-0.546$ \\
\hline Gender & 1.837 & 0.281 & 3.97 & 0.000 & $1.361-2.480$ \\
\hline Living alone & 0.720 & 0.107 & -2.22 & 0.026 & $0.538-0.962$ \\
\hline Education & 1.192 & 0.029 & 7.11 & 0.000 & $1.136-1.251$ \\
\hline Paraplegic & 1.812 & 0.266 & 4.06 & 0.000 & $1.360-2.416$ \\
\hline Completeness & 0.940 & 0.134 & -0.43 & 0.664 & $0.711-1.242$ \\
\hline \multicolumn{6}{|l|}{ Mediation $^{\mathrm{b}}$} \\
\hline \multicolumn{6}{|l|}{ Age at injury (years) } \\
\hline $17-39$ & 1.046 & 0.102 & 0.47 & 0.642 & $0.865-1.266$ \\
\hline $40-63 / 64$ & 0.933 & 0.094 & -0.69 & 0.489 & $0.766-1.136$ \\
\hline Contribution of each SHC to the total effect (\%) & & & 17-39 years & 40-63/64 years & \\
\hline Pressure ulcer & & & -9.19 & -1.26 & \\
\hline Urinary tract infection & & & -18.08 & -8.57 & \\
\hline Pain & & & 17.45 & 21.97 & \\
\hline Spasticity & & & -1.92 & -1.34 & \\
\hline Bladder & & & 0.12 & 0.03 & \\
\hline Bowel & & & -2.55 & -0.75 & \\
\hline Total mediation percentage ${ }^{d}$ & & & -14.17 & 10.07 & \\
\hline
\end{tabular}

Abbreviation: SHC, secondary health condition.

Italic bold = significant results with $P<0.050$

aDirect effect of key age-related variable; includes covariates and mediators (full model).

bIndirect effect of key age-related variable. Total effect measured in odds ratios (reduced model includes covariates but not mediators) is obtained from product of direct effect (full model with covariates and mediators), as shown in footnote a and indirect effect both measured in odds ratios.

'To determine the importance of each SHC's contribution to the total effect, the mediation percentage of each SHC is interpreted as an absolute value.

dThe aggregate mediation effect can become negative, depending on the sign of the correlations between the included variables.

pension benefits, it has also to be considered that, instead of completely dropping out of the labor force, individuals experiencing SHC might reduce their work time to compensate for SHCs and in turn receive an increase in disability pension benefits.

Although we only found a mediating effect of SHCs (pain) on LMP in individuals with the highest chronological age, it warrants highlighting that pressure ulcer, pain and urinary tract infection were significantly associated with LMP in both models, which is consistent with findings from other studies. ${ }^{5,8}$ This result indicates that pressure ulcer, pain and urinary tract infections are important predictors for LMP but are not consistently associated with the assessed age variables.

\section{Limitations of the study}

Our study contributes to current efforts to better understand the interrelationships between chronological age and age at injury, SHCs and LMP. Understanding this interrelationship is crucial if we are to facilitate and promptly guide the return-to-work process for individuals with SCI in light of their age and SHCs. However, our study also has limitations. First, self-report data are limited in accuracy because of recall bias. Second, the analysis was restricted to a subset of potential covariates and we recognize that other factors such as mobility, presence of vocational counseling and the psychological state of the individual with SCI might also influence the relationship. Third, mediation consists of causal processes that emerge over time. Results based on cross-sectional data do not allow for a causal interpretation of relationships, and our findings need to be validated using longitudinal studies. Finally, it is conceivable that the relationships between SHCs and LMP are reciprocal, that is, LMP also influences SHCs, and that covariates are associated with SHCs. To examine this potential reciprocal relationship, research using longitudinal data would be necessary.

\section{CONCLUSION}

The present study supports the finding that chronological age and age at injury have an influence on whether or not an individual is 
employed. In the oldest age group, the association of chronological age on LMP is partly mediated by having pain, indicating that along with increasing age, chronic pain reduces the likelihood to be employed. In addition, pressure ulcer, pain and urinary tract infections were negatively related to LMP. Therefore, pressure ulcer, pain and urinary tract infection should be carefully considered in rehabilitation efforts to increase LMP in older individuals with SCI.

\section{DATA ARCHIVING}

There were no data to deposit.

\section{CONFLICT OF INTEREST}

The authors declare no conflict of interest.

\section{ACKNOWLEDGEMENTS}

This study has been financed in the framework of the SwiSCI (http: //www. swisci.ch), supported by the Swiss Paraplegic Association. We thank the personnel of the SwiSCI study center and the SwiSCI Steering Committee. The members of the SwiSCI Steering Committee are as follows: Dr Olivier Dériaz (Clinique Romande de Réadaptation, Sion); Dr Michael Baumberger and Dr Hans Peter Gmünder (Swiss Paraplegic Center, Nottwil); Dr Armin Curt and Dr Martin Schubert (University Clinic Balgrist, Zürich); Dr Kerstin Hug and Dr Margret Hund-Georgiadis (REHAB Basel, Basel); Dr Hans Georg Koch and Urs Styger (Swiss Paraplegic Association, Nottwil); Prof. Dr Hardy Landolt (representative for persons with SCI, Glarus); Dr Rita Schaumann-Von Stosch (SUVA, Luzern); Mirjam Brach and Prof. Dr Gerold Stucki (Swiss Paraplegic Research, Nottwil); and Dr Martin Brinkhof and Christine Thyrian (SwiSCI Study Center at Swiss Paraplegic Research, Nottwil). We would also like to express our appreciation to Stefan Staubli, Karl Emmenegger, Dr med. Inge Eriks Hoogland, Dr med. Michael Baumberger and Dr med. Helmut Plunien for assessing the relevant SHCs in relation to employment and Carolina Saskia Ballert for her statistical support.
1 Anderson D, Dumont S, Azzaria L, Le Bourdais M, Noreau L. Determinants of return to work among spinal cord injury patients: a literature review. J Vocat Rehabil 2007; 27: 57-68.

2 Lidal IB, Huynh TK, Biering-Sorensen F. Return to work following spinal cord injury: a review. Disabil Soc 2007; 29: 1341-1375.

3 Ottomanelli L, Lind L. Review of critical factors related to employment after spinal cord injury: implications for research and vocational services. J Spinal Cord Med 2009; 32: 503-531.

4 Hirsh AT, Molton IR, Johnson KL, Bombardier CH, Jensen MP. The relationship of chronological age, age at injury, and duration of injury to employment status in individuals with spinal cord injury. Psychol Injury Law 2009; 2: 263-275.

5 Capoor J, Stein AB. Aging with spinal cord injury. Phys Med Rehabil Clin N Am 2005; 16: 129-161.

6 Groah SL, Charlifue S, Tate D, Jensen MP, Molton IR, Forchheimer M et al. Spinal cord injury and aging: challenges and recommendations for future research. Am J Phys Med Rehabil 2012; 91: 80-93.

7 Baumann WA, Waters RL. Aging with a spinal cord inuryKemp BJ, Mesqueda LE. Aging With a Disability: What the Clinician Needs to Know. Johns Hopkins University Press: Baltimore, MD, 2004; 153-174.

8 Charlifue S, Jha A, Lammertse D. Aging with spinal cord injury. Phys Med Rehabil Clin N Am 2010; 21: 383-402.

9 Krause JD, Adkins RH. Methodological issues. In: Kemp BJ, Mesqueda LE (eds). Aging With a Disability: What the Clinician Needs to Know. Johns Hopkins University Press: Baltimore, MD, 2004, pp 237-261.

10 Yasuda S, Wehman P, Targett P, Cifu DX, West M. Return to work after spinal cord injury: a review of recent research. Neurorehabilitation 2002; 17: 177-186.

11 Marti A, Reinhardt JD, Graf S, Escorpizo R, Post MW. To work or not to work: labour market participation of people with spinal cord injury living in Switzerland. Spinal Cord 2012; 50: 521-526.

12 Anderson CJ, Vogel LC. Employment outcomes of adults who sustained spinal cord injuries as children or adolescents. Arch Phys Med Rehabil 2002; 83: 791-801.

13 Post MW, Brinkhof MW, von Elm E, Boldt C, Brach M, Fekete C et al. Design of the Swiss Spinal Cord Injury Cohort Study. Am J Phys Med Rehabil 2011; 90: S5-16.

14 Kalpakjian CZ, Scelza WM, Forchheimer MB, Toussaint LL. Preliminary reliability and validity of a Spinal Cord Injury Secondary Conditions Scale. J Spinal Cord Med 2007; 30: 131-139.

15 StataCorp. Stata Statistical Software: Release 13. StataCorp LP: College Station, TX, USA, 2013.

16 Stekhoven DJ, Buhlmann P. MissForest-non-parametric missing value imputation for mixed-type data. Bioinformatics 2012; 28: 112-118.

17 Karlson KB, Holm A. Decomposing primary and secondary effects: a new decomposition method. Res Soc Stratif Mobil 2011; 29: 221-237.

18 Kohler U, Karlson KB, Holm A. Comparing coefficients of nested nonlinear probability models. Stata J 2011; 11: 420-438.

19 Pagan R. Part-time work among older workers with disabilities in Europe. Public Health 2009; 123: 378-383.

20 Krause JS. Aging and life adjustment after spinal cord injury. Spinal Cord 1998; 36: 320-328. 